\title{
SUBPRODUTO DA INDÚSTRIA DE ALUMÍNIO COMO AMENIZANTE DE SOLOS CONTAMINADOS COM CÁDMIO E CHUMBO(1)
}

\author{
Enio Tarso de Souza $\operatorname{Costa}^{(2)}$, Luiz Roberto Guimarães Guilherme ${ }^{(3)}$, \\ Nilton Curi ${ }^{(3)}$, Luiz Carlos Alves de Oliveira ${ }^{(4)}$, Elton Luiz Visioli ${ }^{(5)}$ \\ \& Guilherme Lopes ${ }^{(5)}$
}

\section{RESUMO}

\begin{abstract}
A poluição do solo com elementos-traço tem sido motivo de preocupação nos últimos anos, o que justifica melhor conhecimento da disponibilidade desses elementos no ambiente, visando amenizar seus efeitos em áreas contaminadas. Este trabalho teve como objetivo avaliar o desempenho de um subproduto da indústria de alumínio como amenizante de solos contaminados com $\mathrm{Cd}$ e $\mathrm{Pb}$. Foram utilizados um Neossolo Quartzarênico $\left(930 \mathrm{~g} \mathrm{~kg}^{-1}\right.$ de areia, $20 \mathrm{~g} \mathrm{~kg}^{-1}$ de silte e $50 \mathrm{~g} \mathrm{~kg}^{-1}$ de argila) e um Latossolo Vermelho $\left(360 \mathrm{~g} \mathrm{~kg}^{-1}\right.$ de areia, $100 \mathrm{~g} \mathrm{~kg}^{-1} \mathrm{de} \mathrm{silte}$ e $540 \mathrm{~g} \mathrm{~kg}^{-1}$ de argila) contendo $15 \%$ de solo contaminado com $\mathrm{Cd}$ e $\mathrm{Pb}$. Foram feitas cinco repetições testando-se o efeito da aplicação do subproduto in natura a $0 ; 0,25 ; 0,50 ; 1,00 ;$ e $2,00 \%$. Para comparação, utilizaram-se calcário, silicato e turfa a 0,$25 ; 0,50$; e $2,00 \%$, respectivamente, e cada um dos solos sem contaminação. Cultivou-se B. decumbens, fazendo coletas de lixiviado e determinando o pH e a CE. As concentrações de $\mathrm{Cd}$ e $\mathrm{Pb}$ foram avaliadas no lixiviado não-filtrado e filtrado $(0,45 \mu \mathrm{m})$. Avaliaram-se a produção de matéria seca de raízes (MSR) e da parte aérea (MSPA) e as quantidades de $\mathrm{Cd}$ e $\mathrm{Pb}$ em ambas após digestão nitroperclórica. Os amenizantes contribuíram para aumentar o pH dos lixiviados do Neossolo Quartzarênico e do Latossolo Vermelho, tendo este último apresentado menores valores de condutividade eletrolítica quando comparado ao primeiro. Os teores de Cd nos lixiviados filtrados (fração solúvel) foram os mesmos dos lixiviados nãofiltrados, enquanto os de $\mathrm{Pb}$ apresentaram diferenças. As produções de MSR e MSPA aumentaram com o aumento das taxas de aplicação do subproduto, e a quantidade de $\mathrm{Cd}$ na MSPA da $B$. decumbens foi maior que a de $\mathrm{Pb}$.
\end{abstract}

Termos de indexação: elementos-traço, remediação, lixiviado, matéria seca.

\footnotetext{
(1) Extraído da Dissertação de Mestrado apresentada pelo primeiro autor ao Departamento de Ciência do Solo da Universidade Federal de Lavras - UFLA. Financiado pela CAPES e ALCOA. Recebido para publicação em abril de 2008 e aprovado em setembro de 2008.

${ }^{(2)}$ Doutorando do Departamento de Ciência do Solo da Universidade Federal de Lavras - UFLA. Caixa Postal 37, CEP 37200-000 Lavras (MG). Bolsista da FAPEMIG. E-mail: eniotarso@yahoo.com.br

(3) Professor do Departamento de Ciência do Solo, UFLA. Bolsista do CNPq. E-mails: guilherm@ufla.br; niltcuri@ufla.br

(4) Professor do Departamento de Química, UFLA. Bolsista do CNPq. E-mail: luizoliveira@ufla.br

(5) Alunos de Iniciação Científica do Departamento de Ciência do Solo, UFLA. Bolsista CNPq. E-mails: eltonvisioli@yahoo.com.br; guilhermlopes@yahoo.com.br
} 


\title{
SUMMARY: ALUMINUM INDUSTRY BY-PRODUCT AS AN AMENDMENT FOR CADMIUM AND LEAD-CONTAMINATED SOILS
}

\begin{abstract}
Soil pollution with trace elements has been of great concern in the last years due to the increase in contaminated areas, which calls for a better understanding of trace element availability and environmental remediation. This study evaluated the performance of an aluminum industry by-product as soil amendment in $\mathrm{Cd}$ - and Pb-contaminated soils. Samples of a sandy (50 $\mathrm{g} \mathrm{kg}^{-1}$ clay) and a clayey (540 $\mathrm{g} \mathrm{kg}^{-1}$ clay) soil were mixed with polluted soil (15\%) with high $\mathrm{Cd}$ and $\mathrm{Pb}$ concentrations and then treated with increasing doses: 0 , $0.25,0.50,1.00$, and $2.00 \%$ (dry weight basis) - of an Al industry by-product. Additional treatments for comparison purposes consisted of: lime, a silicate by-product and turf, at rates of $0.25,0.50$, and $2.00 \%$ respectively, as well as the non-contaminated soils. Plant and soil parameters were evaluated as follows: i) root and shoot dry matter production of Brachiaria decumbens and the respective $C d$ and $\mathrm{Pb}$ concentrations; and, ii) soil $\mathrm{Cd}$ and $\mathrm{Pb}$ concentrations, as well as the $\mathrm{pH}$ and the electrolytic conductivity (EC) of soil leachates. Cadmium and lead concentrations were measured in both unfiltered and $0.45 \mu \mathrm{m}$-filtered leachates, and $\mathrm{Cd}$ and $\mathrm{Pb}$ amounts in the plant roots and shoots were measured after nitric-perchloric digestion. Metal analysis were performed by either flame or graphite furnace atomic absorption spectrophotometry. Increasing the application rates of the Al industry by-product caused an increase in $\mathrm{pH}$ of the leachates and yielded higher $\mathrm{EC}$ values in the sandy than in the clayey soil. Unlike $\mathrm{Cd}$, the $\mathrm{Pb}$ concentration differed between filtered and non-filtered soil leachates. The Al industry by-product favored the root and shoot dry matter production of $B$. decumbens and reduced $C d$ concentrations in the latter ( $\left.\mathrm{mg} \mathrm{kg}^{-1}\right)$ while the $\mathrm{Pb}$ concentration was not significantly altered.
\end{abstract}

Index terms: trace elements, remediation, leachate, dry matter.

\section{INTRODUÇÃO}

A poluição do solo com elementos-traço tem sido motivo de preocupação nos últimos anos, devido ao aumento dos registros de áreas contaminadas. Essas áreas podem colocar em risco a sustentabilidade do ambiente por serem alguns desses elementos persistentes, acumulativos e maléficos aos organismos vivos (Kabata-Pendias \& Pendias, 2001).

A mobilidade desses elementos-traço e, conseqüentemente, a sua toxicidade estão relacionadas à capacidade do solo de mantê-los retidos em sua fase sólida, tornando-os indisponíveis para serem absorvidos pelas plantas, erodidos e, ou, lixiviados (McBride, 1994). A grande complexidade e heterogeneidade dos solos resulta em uma gama de parâmetros que interagem entre si, exigindo estudos bastante criteriosos para a tomada de decisões com relação à reabilitação de determinada área.

Várias são as técnicas empregadas na remediação de áreas contaminadas (vitrificação, lavagem do solo, cobertura do solo, escavação e fitorremediação) (Accioly \& Siqueira, 2000, Mulligan et al., 2001). Na avaliação dessas áreas, deve-se considerar uma série de fatores não só relacionados à técnica em si, mas também à área e às exigências dos órgãos ambientais (Vangronsveld \& Ruttens, 1999). Uma técnica, por si só, muitas vezes, não é eficaz, devendo ser associada a outra para a obtenção de melhores resultados. $\mathrm{Na}$ fitorremediação, tem sido muito estudado o emprego de plantas tolerantes em associação com amenizantes numa técnica mista denominada fitoestabilização (Vangronsveld \& Ruttens, 1999; Accioly \& Siqueira, 2000). Dentre os amenizantes mais utilizados, podem ser citados o calcário, o gesso, o fosfato, os óxidos de $\mathrm{Fe}$ e Al, compostos orgânicos, a beringita, e as cinzas (Mulligan et al., 2001; Lombi et al., 2002a,b; Ciccu et al., 2003; Accioly et al., 2004; Lombi et al., 2004; Bertocchi et al., 2006; Friesl et al., 2006; Pérez-deMora et al., 2007).

A remediação de áreas contaminadas com elementos-traço utilizando-se os mais diversos subprodutos tem sido considerada como uma alternativa promissora em função de uma eficiência já comprovada de muito desses subprodutos e também da grande relação benefício/custo decorrente de seu uso (Friesl et al., 2006; Pérez-de-Mora et al., 2007).

Vários estudos foram feitos com o intuito de avaliar o uso de diferentes resíduos e, ou, subprodutos nos solos visando reduzir a concentração de elementostraço na solução do solo e minimizar o impacto gerado pela deposição de grande quantidade de rejeitos em áreas isoladas (Gupta \& Sharma, 2002; Lombi et al., 2002b). Segundo Gupta \& Sharma (2002), um dos subprodutos industriais derivados do processamento do alumínio tem sido utilizado como eficiente adsorvente de elementos-traço - a lama da mineração de $\mathrm{Al}$, também conhecida como lama vermelha, ou 
"red mud", ou resíduo da bauxita (Lombi et al., 2002a,b; Ciccu et al., 2003; Lombi et al., 2004). Rico em óxidos de ferro, esse subproduto apresenta alto potencial em fixar tais elementos e, por isso, tem despertado o interesse em ser testado como amenizante do solo. Porém, há poucas informações quanto à eficácia e à longevidade de seu uso, mormente em condições tropicais.

Não há na literatura estimativa da quantidade da lama da mineração de $\mathrm{Al}$ gerada no Brasil, mas podem ser feitas considerando alguns trabalhos e os resultados de estatísticas do Brasil referentes a 2005, que constam no Anuário Mineral Brasileiro (DNPM, 2006), realizadas pelo Departamento Nacional de Produção Mineral (DNPM). A produção bruta do minério com um teor de $35,30 \%$ de $\mathrm{Al}_{2} \mathrm{O}_{3}$ foi de 31,19 milhões de toneladas, resultando em cerca de 11,01 milhões de toneladas do metal. Considerando que $1 \mathrm{t}$ de alumínio extraído resulta em 1,5 t de lama (Brunori et al., 2005), estima-se que a produção de lama no Brasil, em 2005, foi de aproximadamente 16,52 milhões de toneladas. Considerando a reserva lavrável, o potencial de geração do rejeito é de 3,24 bilhões de toneladas. Esse material vem sendo depositado em barragens de rejeitos com fundo impermeabilizado, inutilizando grandes áreas para sua construção. Esses depósitos constituem um passivo ambiental para a empresa, além do risco associado ao enorme volume de material armazenado (Brunori et al., 2005), e a solução de estocagem economicamente não recomendada devido aos custos para construção e manutenção.

Considerando-se o potencial de utilização de resíduos como amenizantes de solos contaminados, este trabalho teve como objetivo avaliar o desempenho de um subproduto da indústria de alumínio como amenizante de solos contaminados com $\mathrm{Cd}$ e $\mathrm{Pb}$.

\section{MATERIAL E MÉTODOS}

Foram utilizados dois solos com textura, teor de matéria orgânica e mineralogia contrastante: um Neossolo Quartzarênico (RQ), contendo $930 \mathrm{~g} \mathrm{~kg}^{-1}$ de areia, $20 \mathrm{~g} \mathrm{~kg}^{-1}$ de silte e $50 \mathrm{~g} \mathrm{~kg}^{-1}$ de argila, e um Latossolo Vermelho (LV), contendo $360 \mathrm{~g} \mathrm{~kg}^{-1}$ de areia, $100 \mathrm{~g} \mathrm{~kg}^{-1}$ de silte e $540 \mathrm{~g} \mathrm{~kg}^{-1}$ de argila. Os teores de matéria orgânica ( $\mathrm{dag} \mathrm{kg}^{-1}$ ) do RQ e do LV foram de 1,2 e 2,8, respectivamente. Com base no resultado do ataque sulfúrico, o teor de óxidos $\left(\mathrm{g} \mathrm{kg}^{-1}\right)$ do RQ foi de 30,6 de $\mathrm{SiO}_{2}, 35,8$ de $\mathrm{Al}_{2} \mathrm{O}_{3}, 11,0$ de $\mathrm{Fe}_{2} \mathrm{O}_{3}, 4,7$ de $\mathrm{TiO}_{2}$ e $0,0 \mathrm{P}_{2} \mathrm{O}_{5}$; e do $\mathrm{LV}$ foi de 93,2 de $\mathrm{SiO}_{2}, 258,4$ de $\mathrm{Al}_{2} \mathrm{O}_{3}, 95,1$ de $\mathrm{Fe}_{2} \mathrm{O}_{3}, 19,9$ de $\mathrm{TiO}_{2}$, e 0,8 de $\mathrm{P}_{2} \mathrm{O}_{5}$. Adicionou-se a esses solos outro contaminado com elementos-traço restante de atividades de mineração. O solo contaminado foi misturado a cada um nãocontaminado, a fim de se obterem teores elevados de elementos-traço no substrato final, sem comprometer o desenvolvimento das plantas. A proporção usada foi
$1,5 \mathrm{~kg}$ de solo contaminado para $8,5 \mathrm{~kg}$ de solo nãocontaminado, resultando em um solo com $15 \%$ de contaminação.

Utilizaram-se, como testemunhas, os dois tipos de solo sem contaminação e os solos contaminados sem nenhum tipo de amenizante. Para comparação, foram também utilizados dois amenizantes inorgânicos (calcário na proporção de $0,25 \%$ e um silicato a 0,50 \%) e um orgânico (turfa a 2,00 \%). A lama da mineração de $\mathrm{Al}$ foi usada nas proporções de $0,25,0,50$, 1,00 e $2,00 \%$, com base em peso, correspondendo a 5 , 10, 20 e $40 \mathrm{t} \mathrm{ha}^{-1}$. Essas proporções foram feitas, considerando que o amenizante será incorporado ao solo em uma profundidade de 0,20 m. Os solos e os amenizantes usados foram previamente secos ao ar e passados em peneira com malha de $2 \mathrm{~mm}$ de diâmetro.

A lama da mineração de $\mathrm{Al}$ é um material alcalino que apresenta $\mathrm{pH}$ em água $(1: 2,5)$ igual a 10,00 $( \pm 0,00)$. Com base no resultado do ataque sulfúrico, o teor de óxidos da lama da mineração de $\mathrm{Al}\left(\mathrm{g} \mathrm{kg}^{-1}\right)$ foi de 157,6 de $\mathrm{SiO}_{2}, 316,8$ de $\mathrm{Al}_{2} \mathrm{O}_{3}, 155,3$ de $\mathrm{Fe}_{2} \mathrm{O}_{3}$, 30,6 de $\mathrm{TiO}_{2}, 2,0$ de $\mathrm{P}_{2} \mathrm{O}_{5}$. As concentrações semitotais de $\mathrm{Cd}$ e $\mathrm{Pb}$ na lama da mineração de $\mathrm{Al}$ extraídas usando a metodologia USEPA 3051A foram de $19,92 \mu \mathrm{g} \mathrm{kg}^{-1}$ e $69,39 \mathrm{mg} \mathrm{kg}^{-1}$, respectivamente (USEPA, 1998). Mais detalhes da caracterização desse material encontram-se em Costa et al. (2008).

As abreviações que identificam os tratamentos usados e suas respectivas descrições são as seguintes: RQ: Neossolo Quartzarênico, LV: Latossolo Vermelho, SNC: solo não-contaminado, LMA: lama da mineração de Al, Cal: calcário, Sil: silicato, Tur: turfa. As abreviações foram dispostas colocando-se a abreviação do nome do solo seguida da dose e da abreviação do nome do amenizante. Os tratamentos estão identificados da seguinte forma: RQ SNC; RQ 0,00 LMA; RQ 0,25 LMA; RQ 0,50 LMA; RQ 1,00 LMA; RQ 2,00 LMA; RQ 0,25 Cal; RQ 0,50 Sil; RQ 2,00 Tur; LV SNC; LV 0,00 LMA; LV 0,25 LMA; LV 0,50 LMA; LV 1,00 LMA; LV 2,00 LMA; LV 0,25 Cal; LV 0,50 Sil; e LV 2,00 Tur.

Para a montagem do experimento, os vasos foram confeccionados com garrafas de polietileno tereftalato (PET), com $2 \mathrm{dm}^{3}$ de capacidade volumétrica. Elas foram cortadas aproximadamente ao meio, de modo a obter o vaso onde foi acondicionado o solo na parte superior e um coletor de lixiviados na parte inferior. As tampas das garrafas foram perfuradas e, antes de serem preenchidas com o solo, foi colocada uma lã de vidro para possibilitar a coleta de um lixiviado com menor quantidade de materiais particulados. A quantidade de solo usada em cada vaso foi de $1,5 \mathrm{~kg}$ de Neossolo Quartzarênico e 1,1 kg de Latossolo Vermelho, ambos ocupando um volume de aproximadamente $1 \mathrm{dm}^{3}$.

Após a mistura dos amenizantes nos solos, os vasos foram mantidos durante 15 dias com um nível de 
umidade próximo do nível de capacidade de campo para que se processassem as reações dos amenizantes com os substratos. Esse período foi determinado em préexperimento, em que quantidades de lama da mineração de $\mathrm{Al}$ foram adicionadas aos solos e as leituras de $\mathrm{pH}$ feitas a cada dois dias, consideradas estáveis quando as variações nas leituras foram inferiores a 0,2 unidade de $\mathrm{pH}$. Encerrado o período de incubação, retiraram-se $20 \mathrm{~cm}^{3}$ do substrato e, em seguida, procedeu-se à semeadura da Brachiaria decumbens. As amostras simples contendo $20 \mathrm{~cm}^{3}$ do substrato coletadas dos cinco vasos pertencentes a cada tratamento foram homogeneizadas, de modo a se obter uma amostra composta. Essas amostras foram secas ao ar para posterior análise de fertilidade, segundo Vettori (1969) e Embrapa (1997), bem como para a determinação das quantidades semitotais de $\mathrm{Cd}$ e $\mathrm{Pb}$ pelo método USEPA 3051A da Agência de Proteção Ambiental dos Estados Unidos (USEPA, 1998). Os resultados das análises de fertilidade e dos teores semitotais encontram-se nos quadros 1 e 2 , respectivamente.
As leituras de $\mathrm{Cd}$ e $\mathrm{Pb}$ nos extratos foram feitas usando-se espectrofotômetro de absorção atômica (EAA) de chama (leituras na faixa de concentração de $\mathrm{mg} \mathrm{L}^{-1}$ ), ou com forno de grafite (leituras na faixa de concentração de $\left.\mu \mathrm{g} \mathrm{L}^{-1}\right)$. O controle de qualidade das análises foi feito por meio de amostras de solo com concentrações de $\mathrm{Cd}$ e $\mathrm{Pb}$ conhecidas do North American Proficiency Test Program da Soil Science Society of America.

Para garantir uma germinação homogênea das sementes, procedeu-se à quebra da dormência (Brasil, 1992) para posterior semeadura. A escolha da Brachiaria decumbens ocorreu em função do seu crescimento bastante agressivo, proporcionando uma rápida cobertura do solo. Após a germinação, foram feitos desbastes, deixando-se seis plantas por vaso.

Após a semeadura, nos primeiros 10 dias, as irrigações foram feitas com solução de sulfato de cálcio $\left(\mathrm{CaSO}_{4} 2 \mathrm{H}_{2} \mathrm{O}\right) 1^{-4} \mathrm{~mol} \mathrm{~L}^{-1}$, para estimular o desenvolvimento de raízes, e depois com água deionizada, procurando-se manter um fluxo

Quadro 1. Atributos químicos dos solos antes da semeadura

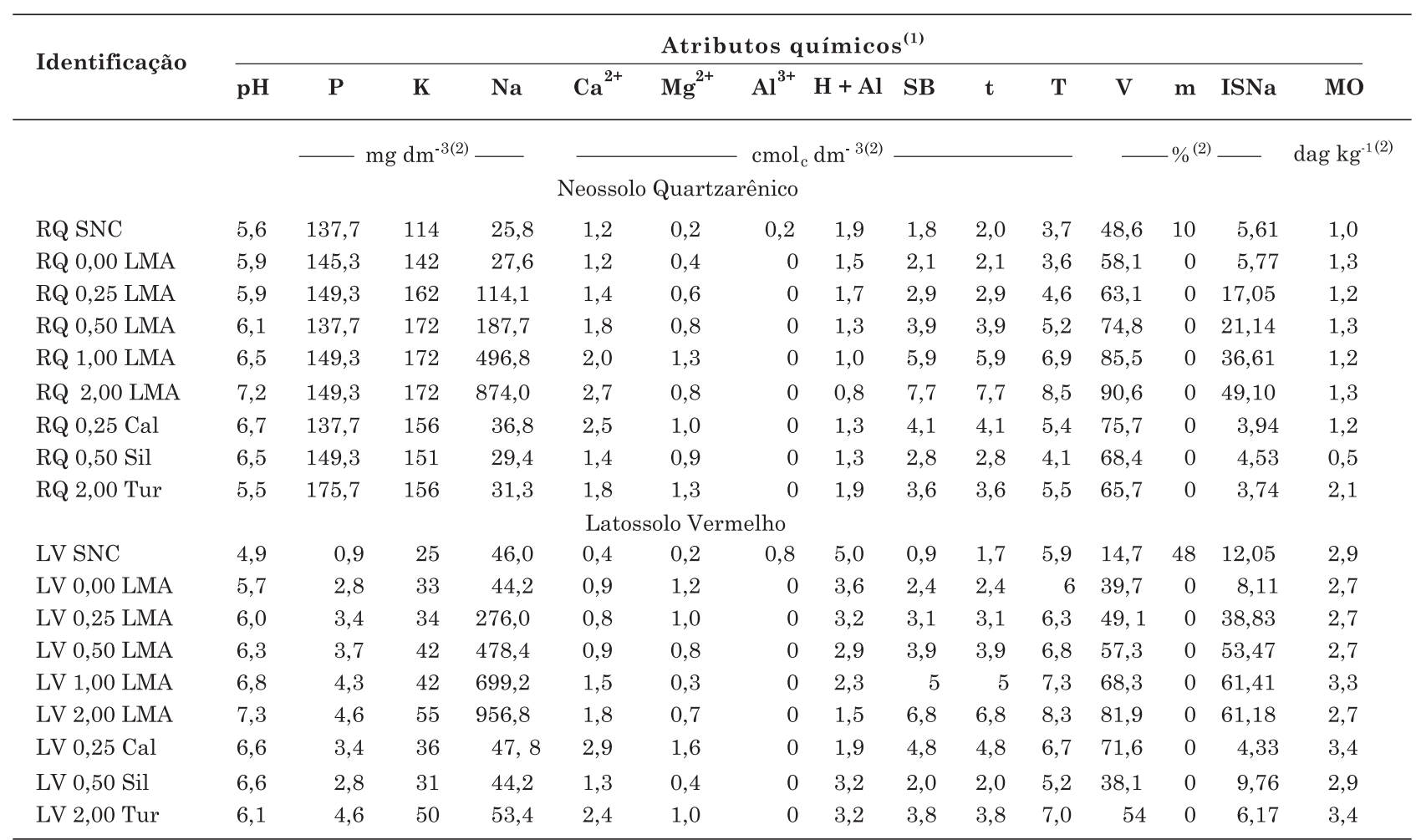

(1) Atributos químicos: pH: pH em água (relação 1: 2,5); $\mathrm{P}$ (fósforo), $\mathrm{K}$ (potássio), Na (sódio): extrator Mehlich-1; Ca (cálcio), Mg (magnésio), Al (alumínio): extrator $\mathrm{KCl} 1 \mathrm{~mol} \mathrm{~L}{ }^{-1} ; \mathrm{H}+\mathrm{Al}$ (hidrogênio + alumínio): extrator SMP; SB (soma de bases trocáveis); t (capacidade de troca catiônica efetiva); T (capacidade de troca catiônica em pH 7,0); V (índice de saturação de bases); m (índice de saturação de alumínio); ISNa (índice de saturação de sódio); $\mathrm{MO}$ (matéria orgânica): oxidação: $\mathrm{Na}_{2} \mathrm{Cr}_{2} \mathrm{O}_{7} 0,67$ mol $\mathrm{L}^{-1}+\mathrm{H}_{2} \mathrm{SO}_{4}$ 5 mol L ${ }^{-1}$. Atributos como: pH, P, K, Na, Ca, Mg, Al e H + Al foram feitos conforme Embrapa (1997), MO segundo Vettori (1969). (2) Os valores são referentes a uma amostra composta obtida de cinco amostras simples retiradas das cinco parcelas de cada tratamento após incubação de 15 dias, com os solos mantidos com umidade próxima à capacidade de campo. RQ: Neossolo Quartzarênico, LV: Latossolo Vermelho, SNC: solo não-contaminado, LMA: lama da mineração de Al, Cal: calcário, Sil: silicato, Tur: turfa e 0,00;0,25;0,50; 1,00; e 2,00: proporção em porcentagem dos amenizantes aplicados correspondendo a 0, 5, 10, 20, e $40 \mathrm{t} \mathrm{ha}^{-1}$. 
Quadro 2. Teores semitotais de cádmio e chumbo dos tratamentos antes da semeadura

\begin{tabular}{|c|c|c|}
\hline \multirow{2}{*}{ Tratamento } & \multicolumn{2}{|c|}{ Determinação $^{(1)}$} \\
\hline & Cd & $\mathbf{P b}$ \\
\hline & \multicolumn{2}{|c|}{$-\mathrm{mg} \mathrm{kg}^{-1}$} \\
\hline & \multicolumn{2}{|c|}{ Neossolo Quartzarênico } \\
\hline RQ SNC & 0,33 & 1,75 \\
\hline RQ 0,00 LMA & 14,11 & 114,27 \\
\hline RQ 0,25 LMA & 14,55 & 132,73 \\
\hline RQ 0,50 LMA & 12,69 & 95,03 \\
\hline RQ 1,00 LMA & 17,23 & 98,81 \\
\hline RQ 2,00 LMA & 13,49 & 109,96 \\
\hline $\mathrm{RQ} 0,25 \mathrm{Cal}$ & 13,32 & 96,75 \\
\hline RQ 0,50 Sil & 14,71 & 106,17 \\
\hline \multirow[t]{2}{*}{ RQ 2,00 Tur } & 13,63 & 101,11 \\
\hline & \multicolumn{2}{|c|}{ Latossolo Vermelho } \\
\hline LV SNC & 0,02 & 8,95 \\
\hline LV 0,00 LMA & 17,30 & 128,18 \\
\hline LV 0,25 LMA & 16,36 & 120,99 \\
\hline LV 0,50 LMA & 17,56 & 117,26 \\
\hline LV 1,00 LMA & 16,26 & 121,01 \\
\hline LV 2,00 LMA & 17,34 & 137,88 \\
\hline $\mathrm{LV} 0,25 \mathrm{Cal}$ & 15,75 & 120,09 \\
\hline LV 0,50 Sil & 17,71 & 128,66 \\
\hline LV 2,00 Tur & 17,54 & 128,66 \\
\hline
\end{tabular}

(1) Determinações das quantidades semitotais de metais pelo método USEPA 3051A (USEPA, 1998) de uma amostra composta obtida de cinco amostras simples retiradas das cinco parcelas de cada tratamento, após incubação de 15 dias e com os solos mantidos com umidade próxima à capacidade de campo. RQ: Neossolo Quartzarênico, LV: Latossolo Vermelho, SNC: solo não-contaminado, LMA: lama da mineração de Al, Cal: calcário, Sil: silicato, Tur: turfa e 0,$00 ; 0,25 ; 0,50 ; 1,00$ e 2,00: proporção em porcentagem dos amenizantes aplicados correspondendo a $0,5,10,20$ e 40 toneladas por hectare.

descendente para evitar que houvesse uma concentração de sais na superfície devido à evaporação, o que poderia impedir a germinação das sementes e o desenvolvimento das plantas.

Foram feitas três adubações via fertirrigação, sendo a primeira aos 10 dias após a semeadura e as outras duas com 22 e 35 dias. Foram realizadas também duas aplicações foliares de sulfato ferroso amoniacal [ $\left.\mathrm{Fe}\left(\mathrm{NH}_{4}\right)_{2}\left(\mathrm{SO}_{4}\right)_{2} 6 \mathrm{H}_{2} \mathrm{O}\right]$ na dose de $1 \mathrm{~g} \mathrm{~L}^{-1}$, devido aos sintomas de deficiência de ferro. As doses de nutrientes aplicadas foram as seguintes: 300 de $\mathrm{N}$, 200 de $\mathrm{P}, 300$ de $\mathrm{K}, 75$ de Ca, 30 de $\mathrm{Mg}, 50$ de S, 0,5 de $\mathrm{B}, 1,5$ de $\mathrm{Cu}, 5$ de Fe, 10 de $\mathrm{Mn}$ e 0,1 de Mo (valores em $\mathrm{mg} \mathrm{dm}^{-3}$ ). Com exceção de $\mathrm{N}$ e $\mathrm{K}$, que foram parcelados em três aplicações, os outros nutrientes foram aplicados todos na primeira adubação.

Antes da coleta das plantas (45 dias após a semeadura), aplicou-se uma irrigação com uma lâmina excessiva de água para coleta de lixiviado. Mediram-se os volumes coletados, procedendo-se, em seguida, às leituras de $\mathrm{pH}$ e de condutividade eletrolítica (CE). Uma alíquota do lixiviado foi filtrada em $0,45 \mu \mathrm{m}$ (fração solúvel) e outra simplesmente retirada para leitura de $\mathrm{Cd}$ e $\mathrm{Pb}$ (fração total), usandose EAA de chama e, ou, com forno de grafite.

Na coleta das plantas, 45 dias após a semeadura, separou-se a parte aérea das raízes e ambas foram lavadas com água deionizada. A parte aérea e as raízes foram secas em estufa com circulação forçada de ar, em temperatura de, aproximadamente, $60{ }^{\circ} \mathrm{C}$. Após a secagem, ambas as partes foram pesadas separadamente, para a avaliação da produção de matéria seca de raiz e parte aérea e, logo em seguida, a parte aérea foi triturada para determinação de $\mathrm{Cd}$ e $\mathrm{Pb}$ pela digestão nitroperclórica (Malavolta et al., 1989). Nos extratos da digestão, as leituras de $\mathrm{Cd}$ e $\mathrm{Pb}$ foram feitas utilizando-se EAA de chama $\left(\mathrm{mg} \mathrm{L}^{-1}\right)$ ou com forno de grafite $\left(\mu \mathrm{g} \mathrm{L}^{-1}\right)$. Ressalta-se que não foi feita a digestão das raízes, devido à baixa produção de matéria seca em alguns tratamentos e ao foco do trabalho estar direcionado à avaliação de um amenizante, não sendo o principal alvo a acumulação do elemento pelas plantas e sim a redução de sua fitotoxicidade para a produção de matéria seca para cobertura da área remediada.

O experimento foi composto de um fatorial do tipo 2:9 (dois solos e nove categorias de amenizantes). O delineamento foi inteiramente casualizado, com cinco repetições para cada tratamento, perfazendo um total de 90 parcelas. Para análise estatística dos resultados, utilizou-se o programa Sisvar, no qual processou-se a análise de variância e dos contrastes para as comparações e regressões.

\section{RESULTADOS E DISCUSSÃO}

\section{Efeito dos amenizantes sobre o pH e a $\mathrm{CE}$ dos lixiviados de solo}

$\mathrm{O}$ pH dos lixiviados (Figura 1) dos tratamentos com Neossolo Quartzarênico e Latossolo Vermelho, contaminado com $\mathrm{Cd}$ e $\mathrm{Pb}$ e amenizado com a lama da mineração de $\mathrm{Al}$ apresentou comportamento quadrático atingindo valores máximos de 8,5 e 7,9, respectivamente, com a maior dose do amenizante $(2,00 \%)$. Esses resultados evidenciam a capacidade do amenizante em alterar o $\mathrm{pH}$ do solo e do eluente. Resultados semelhantes foram encontrados em um experimento utilizando colunas de lixiviação, nos quais os valores de $\mathrm{pH}$ dos lixiviados encontrados por Ciccu et al. (2003) situaram-se entre 5 e 6 para a coluna que continha somente solo contaminado com $12.245 \mathrm{mg} \mathrm{kg}^{-1}$ de $\mathrm{Pb}, 3.366 \mathrm{mg} \mathrm{kg}^{-1}$ de $\mathrm{Zn}$, $444 \mathrm{mg} \mathrm{kg}^{-1}$ de $\mathrm{Cu}$ e $25 \mathrm{mg} \mathrm{kg}^{-1}$ de $\mathrm{Cd}$, e acima de 8 quando tratou esse solo com cinzas e lama da mineração de $\mathrm{Al}$.

A lama da mineração de Al aplicada a 1,00 e 2,00 \% foi superior aos demais amenizantes (calcário, silicato e turfa) e ao solo não-contaminado para o Neossolo Quartzarênico e somente a 2,00 \% para o Latossolo Vermelho. Os tratamentos contendo o Neossolo 


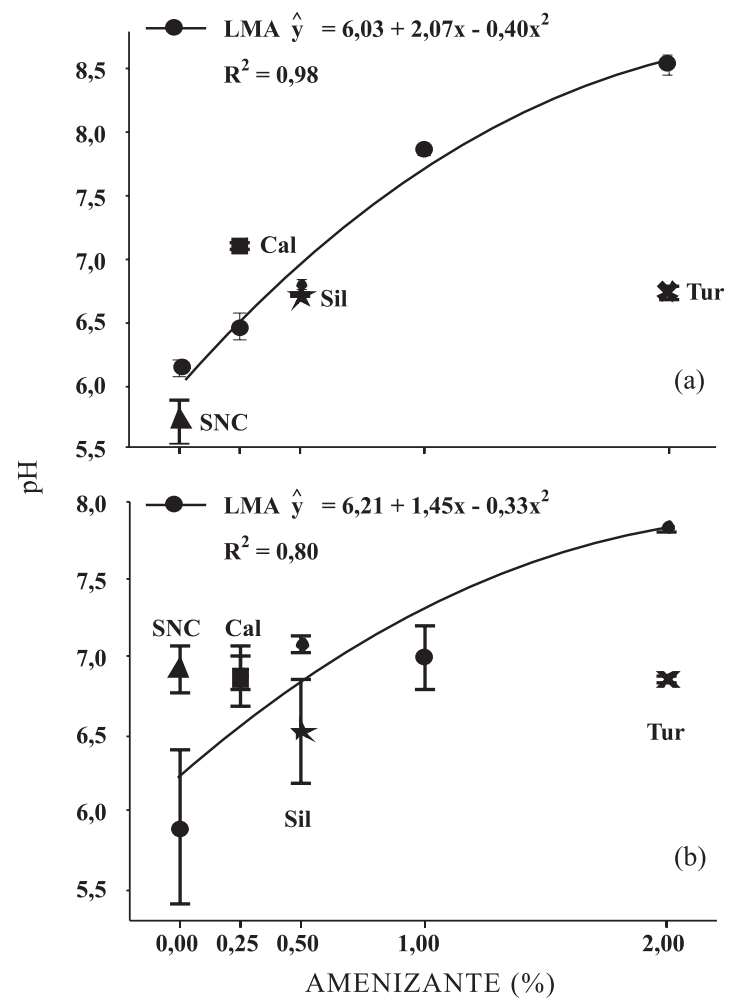

Figura 1. Valores médios de pH nos lixiviados do Neossolo Quartzarênico (a) e do Latossolo Vermelho (b) contaminados com $\mathrm{Cd}$ e $\mathrm{Pb}$ coletados no término do experimento. LMA: lama da mineração de Al, SNC: solo nãocontaminado, Cal: calcário, Sil: silicato, e Tur: turfa.

Quartzarênico resistiram menos à ação dos amenizantes em alterar o $\mathrm{pH}$ do eluente, devido ao menor poder tamponante desse solo, enquanto nos tratamentos em que foi usado o Latossolo Vermelho, essa resistência foi maior, pelo fato de o solo apresentar maior poder tamponante. Isso se deve ao fato do Latossolo Vermelho ser mais argiloso e, portanto, apresentar maior área superficial específica para a retenção de solutos, além de ser rico em minerais como os óxidos e apresentar maior conteúdo de matéria orgânica, quando comparado com o Neossolo Quartzarênico.

O poder alcalinizante do amenizante em estudo foi verificado também por Bertocchi et al. (2006) em trabalho realizado para avaliar, dentre outras variáveis, a capacidade de neutralizar os rejeitos de mina altamente ácidos. Para isso, montaram-se colunas de lixiviação e mediu-se o pH do lixiviado, que variou de 1,94 a 3,03 na coluna que continha o rejeito contaminado de mina, de 4,8 a 6,9 na coluna com rejeito de mina misturado com lama da mineração de $\mathrm{Al}$, e de 5,7 a 7,6 na coluna com rejeito de mina com cinzas.

A condutividade eletrolítica ( $\mathrm{CE}$, em dS $\mathrm{m}^{-1}$ ) dos lixiviados do Neossolo Quartzarênico e do Latossolo Vermelho contaminado com $\mathrm{Cd}$ e $\mathrm{Pb}$ e tratados com lama da mineração de $\mathrm{Al}$ apresentaram comportamentos quadráticos (Figura 2). Vale ressaltar que a dificuldade na uniformidade do volume de lixiviado coletado pode dificultar na visualização dos efeitos dos tratamentos para diversas variáveis analisadas. Dentre estas, tem-se a condutividade eletrolítica, que, espera-se, em volume de lixiviado menor, dentro de determinado tratamento, apresente maior valor. Bertocchi et al. (2006) verificaram, em experimento com colunas de lixiviação, que a condutividade eletrolítica reduziu-se quando o volume da solução percolante aumentou. Os autores constataram variações de 11,13 a $0,6 \mathrm{mS} \mathrm{cm}^{-1}$ (o mesmo que $\mathrm{dS} \mathrm{m} \mathrm{m}^{-1}$ ) na coluna contendo rejeito contaminado de mina; 12,69 a $0,59 \mathrm{mS} \mathrm{cm}^{-1}$ na coluna com rejeito de mina misturado com lama da mineração de Al, e 6,63 a 0,15 mS cm ${ }^{1}$ na coluna contendo rejeito de mina com cinzas.

Pode-se observar na figura 2 que as condutividades eletrolíticas nos lixiviados do Neossolo Quartzarênico apresentaram os maiores valores, em comparação com as do Latossolo Vermelho, que pode reter os íons, quando comparados com o Neossolo Quartzarênico,

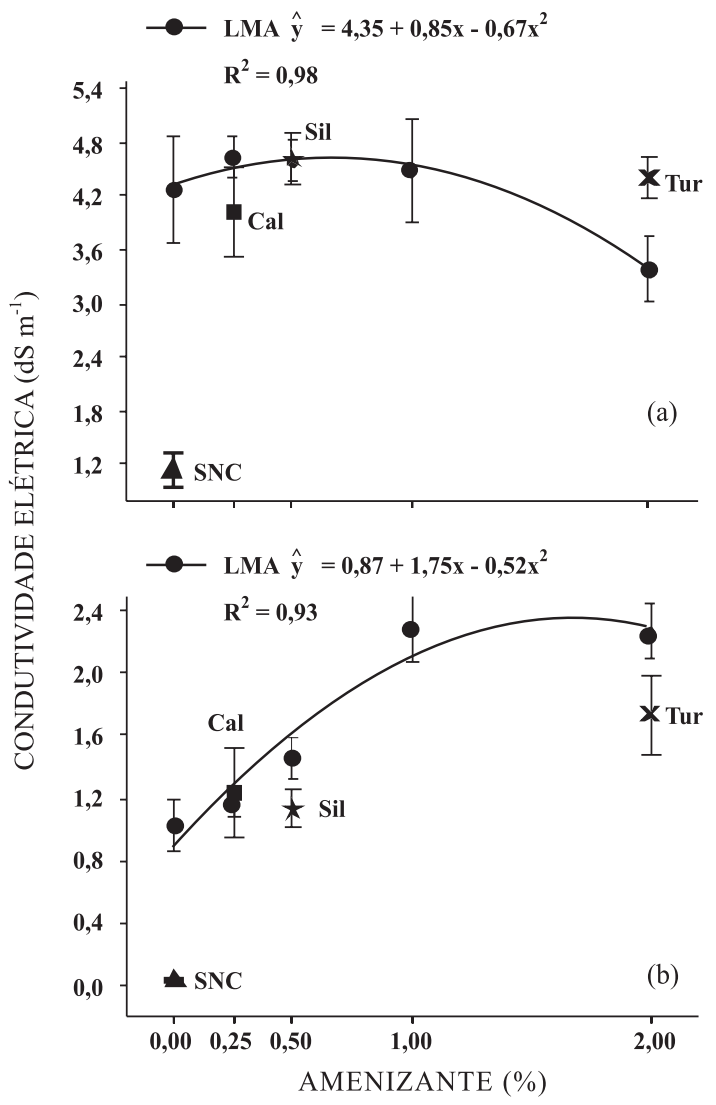

Figura 2. Condutividade eletrolítica $\left(\mathrm{dS} \mathrm{m}^{-1}\right)$ nos lixiviados do Neossolo Quartzarênico (a) e do Latossolo Vermelho (b) contaminados com Cd e $\mathrm{Pb}$ coletados no término do experimento. LMA: lama da mineração de $\mathrm{Al}$, SNC: solo nãocontaminado, Cal: calcário, Sil - silicato e Tur: turfa. 
devido ao seu maior teor de argila, maior área superficial específica, maior quantidade de óxidos e matéria orgânica.

A condutividade eletrolítica no lixiviado aumentou com a maior porcentagem de uso da lama da mineração de Al para o Latossolo Vermelho e para o Neossolo Quartzarênico, exceto para o tratamento a 2,00 \% nesse último solo. Essa redução pode estar relacionada ao alto $\mathrm{pH}$ do lixiviado $(8,5 \pm 0,0)$, o que pode ter contribuído para a precipitação de alguns íons, fazendo com que a condutividade neste caso seja menor. A condutividade eletrolítica de ambos os solos nãocontaminados foi menor que a dos demais tratamentos. No Neossolo Quartzarênico, a condutividade eletrolítica do tratamento com a lama da mineração de $\mathrm{Al}$ foi semelhante à de outros amenizantes (calcário, silicato e turfa), no entanto, no Latossolo Vermelho, a 1,00 e 2,00\%, a CE foi superior. Devido ao maior poder de retenção do Latossolo Vermelho, somente quantidades maiores de amenizantes são requeridas para provocar alterações na condutividade do lixiviados, o que não ocorre para o Neossolo Quartzarênico.

Lombi et al. (2002b) avaliaram o efeito da lama da mineração de $\mathrm{Al}$ na redução da mobilidade e disponibilidade de elementos-traço, comparando-o ao do calcário e ao da beringita. Esses autores concluíram que a aplicação de $2 \%$ de lama funcionou tão bem quanto a aplicação de $5 \%$ de calcário, mas o tratamento com a lama causou um aumento na condutividade eletrolítica dos lixiviados devido ao $\mathrm{NaOH}$ neste material.

No experimento conduzido por Ciccu et al. (2003), mediu-se a condutividade eletrolítica em quatro colunas de lixiviação. Eles encontraram valores inicialmente iguais a $4,6 \mathrm{dS} \mathrm{m}^{-1}$ na primeira coluna com solo contaminado com $\mathrm{Zn}, \mathrm{Cu}, \mathrm{Cd}$ e $\mathrm{Pb} ; 6,7 \mathrm{dS} \mathrm{m}^{-1}$ na segunda coluna com uma mistura de solo contaminado mais cinzas; $17,1 \mathrm{dS} \mathrm{m}^{-1}$ na terceira coluna com uma mistura de solo contaminado mais cinzas e lama da mineração de $\mathrm{Al}$; e $27,8 \mathrm{dS} \mathrm{m}^{-1}$ na quarta com uma mistura de solo contaminado mais lama e gesso. Posteriormente, esses valores tenderam, em todos os casos, a diminuir rapidamente para 0,11 ; 0,$16 ; 0,17$; e $0,30 \mathrm{dS} \mathrm{m}^{-1}$, respectivamente, nas mesmas colunas. Observa-se que os valores iniciais nos tratamentos que continham lama da mineração de Al ficaram acima daqueles encontrados neste estudo, embora essa comparação não tenha sido muito precisa, pois o amenizante foi aplicado individualmente e os solos apresentaram características distintas.

\section{Efeito dos amenizantes sobre os teores de $\mathrm{Cd}$ e Pb nos lixiviados de solo}

As concentrações de $\mathrm{Cd}$ e $\mathrm{Pb}\left(\mathrm{mg} \mathrm{L}^{-1}\right)$ nos lixiviados não-filtrados e nos filtrados em membrana de $0,45 \mu \mathrm{m}$ estão representadas na figura 3. Não houve diferenças nas concentrações de Cd (Figura 3a) nos lixiviados filtrados e não-filtrados. $\mathrm{O} \mathrm{Pb}$ (Figura $3 \mathrm{~b}$ ) apresentou um comportamento diferente daquele do $\mathrm{Cd}$, com maiores concentrações nos lixiviados não-filtrados no solo contaminado sem amenizante (RQ 0,00 LMA) e com a lama da mineração de $\mathrm{Al}$ a 2,00 \% (RQ 2,00 LMA), no Neossolo Quartzarênico, e somente com aplicação da lama da mineração de alumínio a 2,00 \% (LV 2,00 LMA) no Latossolo Vermelho. Isso se deve ao fato de o $\mathrm{Pb}$, quando comparado com o $\mathrm{Cd}$,
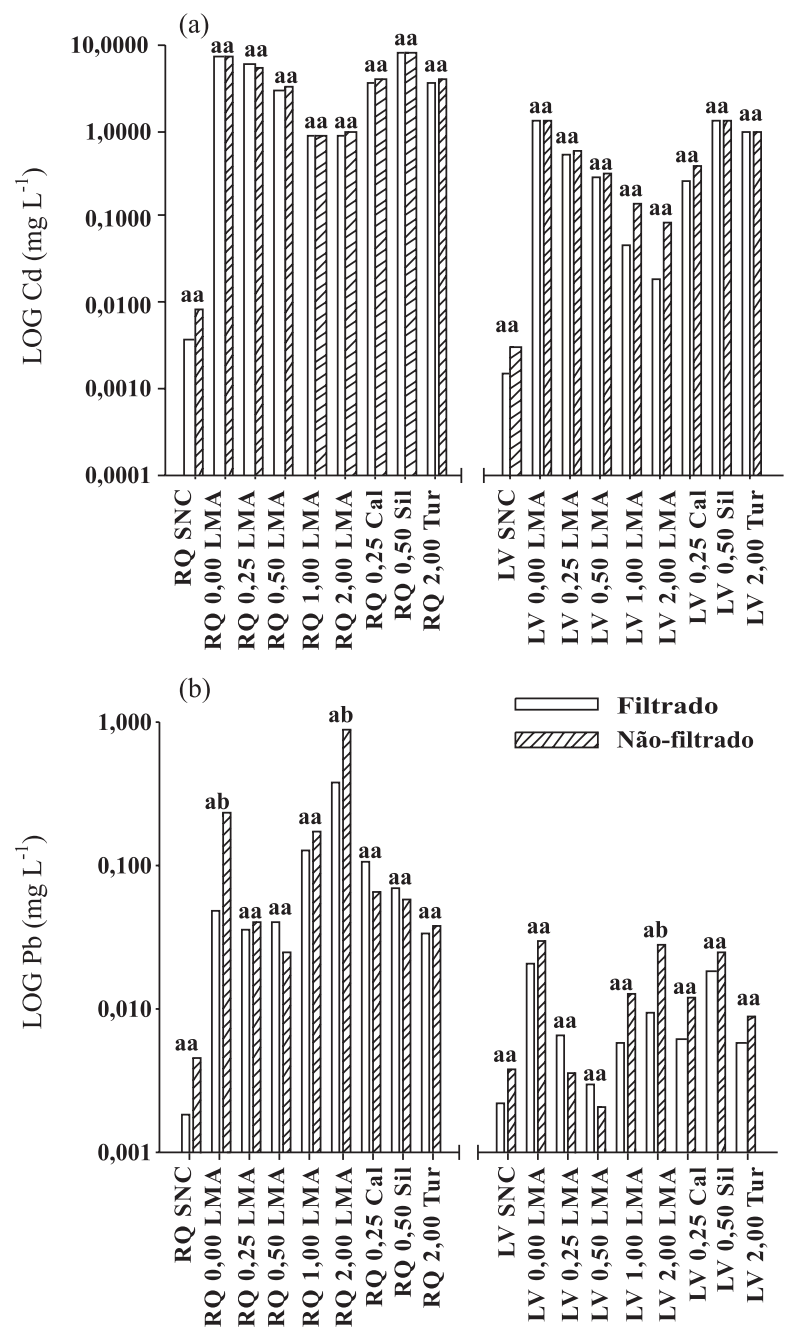

Figura 3. Função logarítmica da concentração de Cd (a) e de $\mathrm{Pb}$ (b) (mg L $\left.\mathrm{m}^{-1}\right)$ nos lixiviados do Neossolo Quartzarênico (RQ) e do Latossolo Vermelho (LV) contaminados com $\mathrm{Cd}$ e $\mathrm{Pb}$ e coletados no término do experimento. Os resultados se referem a leituras de $\mathrm{Cd}$ e de $\mathrm{Pb}$ feitas em uma alíquota de lixiviado filtrado em membrana de $0,45 \mu \mathrm{m}$ e outra não-filtrada, ambas da mesma parcela. LMA: lama da mineração de $\mathrm{Al}, \mathrm{SNC}$ : solo não-contaminado, Cal: calcário, Sil: silicato, Tur: turfa, e 0,00; 0,25; 0,50; 1,00 e 2,00: proporção em porcentagem dos amenizantes aplicados correspondendo a $0,5,10,20$ e $40 \mathrm{t} \mathrm{ha}^{-1}$. As barras, dentro de cada tratamento, seguidas de mesma letra não diferem entre si pelo teste de Tukey $(p<0,05)$. 
apresentar maior afinidade para se ligar a partículas orgânicas e inorgânicas, ficando, neste caso, também presente na forma particulada. Os metais retidos em partículas orgânicas ou inorgânicas ficam retidos na membrana de 0,45 $\mu \mathrm{m}$, no momento da filtragem, reduzindo, assim, suas concentrações no lixiviado filtrado. Como as amostras filtradas e não-filtradas são acidificadas com ácido nítrico concentrado $\left(\mathrm{HNO}_{3}\right)$ para tornar o meio impróprio ao desenvolvimento de fungos durante o armazenamento, os metais, na forma particulada presente no lixiviado que não foi filtrado, são liberados para a solução, resultando em maiores concentrações nas leituras por EAA. Esses resultados sugerem que pode ocorrer uma superestimativa quando se quer determinar os metais biodisponíveis em lixiviados não-filtrados ricos em materiais particulados. Esses metais particulados ficaram inativos até que ocorra no meio mudança que favoreça sua solubilização, quando, então, podem causar toxicidade.

Resultados semelhantes também foram verificados em um experimento em que utilizaram dois lodos do tratamento de água, duas lamas vermelhas e um gesso vermelho como amenizantes de solo contaminado com As e Cu. Lombi et al. (2004) sugerem que não é correto assumir que elementos-traço associados a colóides móveis estão biodisponíveis, e a não-labilidade pode ser importante de várias maneiras devido ao transporte de contaminantes e aos efeitos no ecossistema, porém é um assunto ainda pouco estudado. Se quantidades significativas de elementos-traço associados a colóides não estiverem em equilíbrio com a solução do solo, então o transporte de metais por um meio reativo, como o solo, pode ser subestimado. Similarmente, os riscos de elementos-traço associados a colóides sobre a biota aquática podem ser superestimados, uma vez que uma quantidade significativa de metais medidos na solução está essencialmente na forma não disponível, desde que não ocorram mudanças na labilidade com o tempo. Os autores ainda relatam que os principais fatores que controlam as transformações dos elementos-traço associados a colóides móveis de formas não lábeis para as formas lábeis permanecem ainda não estudados.

Os teores semitotais de $\mathrm{Cd}$ e $\mathrm{Pb}$ encontrados nos solos estão descritos no quadro 2. As quantidades de $\mathrm{Cd}$ e $\mathrm{Pb}\left(\mathrm{mg} \mathrm{kg}^{-1}\right)$ no Neossolo Quartzarênico contaminado foram, em média, 14,22 e 106,85 e, no Latossolo Vermelho, 16,98 e 125,34. Com base nos valores usados para a referência de qualidade de solos, propostos pela Companhia de Tecnologia de Saneamento Ambiental (CETESB, 2005), de $<0,5 \mathrm{mg} \mathrm{kg}^{-1}$ para o $\mathrm{Cd}$ e $17 \mathrm{mg} \mathrm{kg}^{-1}$ para o $\mathrm{Pb}$, podese observar que os solos se encontram com quantidades acima daquelas usadas como referência da qualidade do solo. Embora os solos tenham sido contaminados intencionalmente pela mistura com um solo contaminado por atividade de mineração, essa comparação é feita somente com o intuito de orientar os valores que estão sendo usados neste estudo.
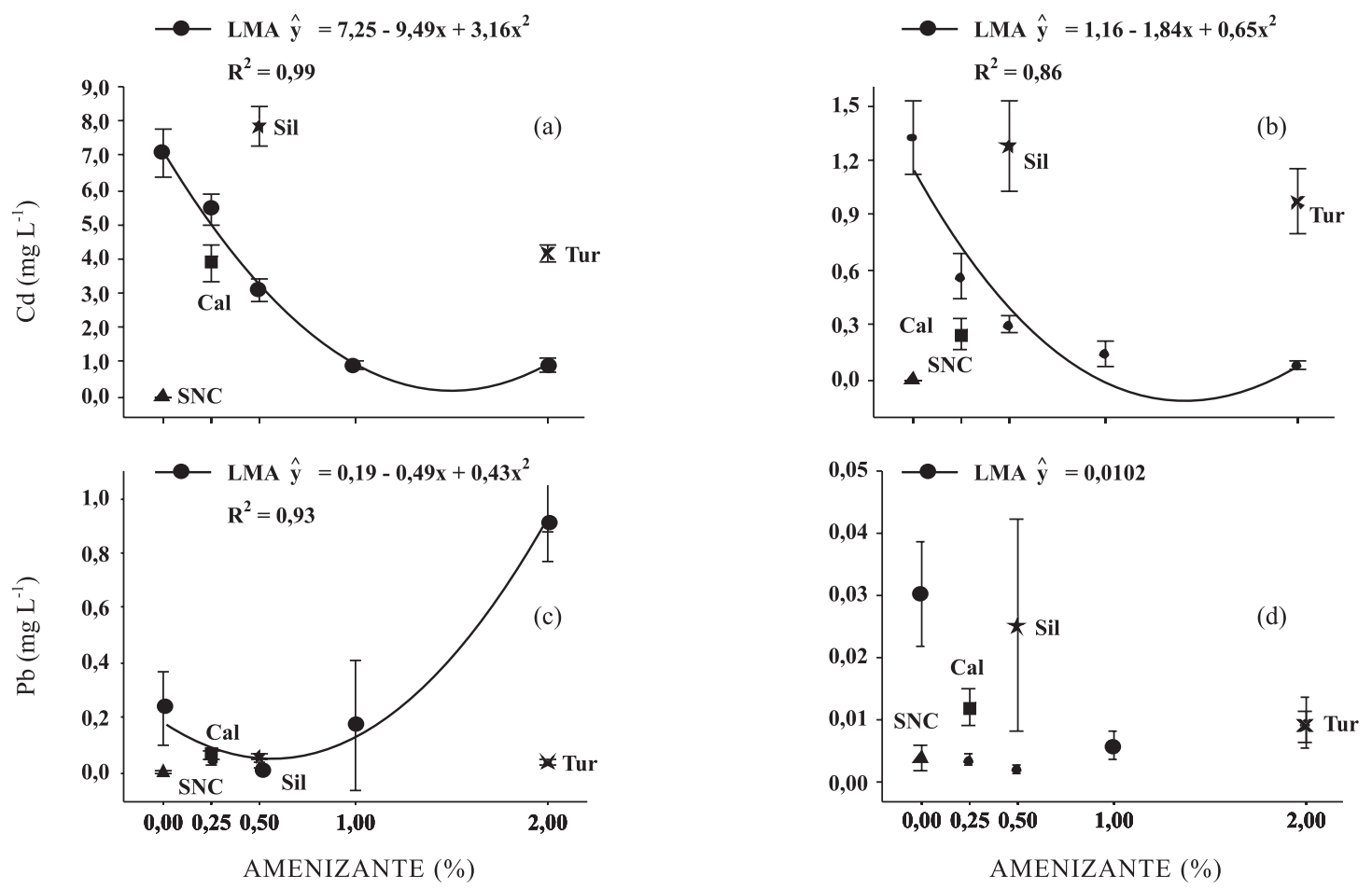

Figura 4. Concentração de $\mathrm{Cd}$ e de $\mathrm{Pb}\left(\mathrm{mg} \mathrm{L}^{-1}\right)$, respectivamente, no lixiviado do Neossolo Quartzarênico (a e c) e do Latossolo Vermelho (b e d) contaminados com $\mathrm{Cd}$ e $\mathrm{Pb}$ e coletados no término do experimento. LMA: lama da mineração de Al, SNC: solo não-contaminado, Cal: calcário, Sil - silicato e Tur: turfa. 
As concentrações de $\mathrm{Cd}$ e $\mathrm{Pb}\left(\mathrm{mg} \mathrm{L}^{-1}\right)$ no lixiviado do Neossolo Quartzarênico e Latossolo Vermelho estão representadas na figura 4. As quantidades de $\mathrm{Cd}$ (Figura 4a) e $\mathrm{Pb}$ (Figura 4c) percoladas foram maiores nos lixiviados do Neossolo Quartzarênico, quando comparados com aqueles do Latossolo Vermelho, sendo as quantidades de $\mathrm{Cd}$ maiores que as de $\mathrm{Pb}$. Vale relembrar que alguns atributos do Latossolo contribuem para reter os metais, como maior teor de argila, maior área de superfície, maior quantidade de óxidos, maior conteúdo de matéria orgânica, e podem contribuir para menor remoção por lixiviação. Estes metais, uma vez retidos na matriz do solo ou do amenizante, não são carreados pela solução percolante, a não ser que ocorra o arraste das próprias partículas orgânicas ou do solo.

Esses resultados corroboram os encontrados no experimento realizado por Silva et al. (2003), no qual avaliou-se a disponibilidade temporal de elementostraço por meio do extrator Mehlich-1, em cinco tipos de solos incubados com diferentes doses de composto urbano. Foi constatado que a disponibilidade dos elementos-traço é afetada pelo teor de argila e de óxidos, além do $\mathrm{pH}$. Este estudo revelou, ainda, que o $\mathrm{Cr}$ foi menos afetado que $\mathrm{Co}, \mathrm{Pb}$ e $\mathrm{Cd}$. No entanto, o comportamento do Co e do $\mathrm{Cd}$ foi inverso ao do $\mathrm{Pb}$. Conforme esses autores, os metais $\mathrm{Pb}$ e $\mathrm{Cr}$ são menos solúveis, ao passo que $\mathrm{Ni} \mathrm{e} \mathrm{Cd} \mathrm{são} \mathrm{relativamente} \mathrm{mais}$ móveis e disponíveis, o que implica maior risco ambiental. Em relação à textura dos solos, os mais tamponados resistem mais às perdas de metais pelo fato de sua adsorção iônica estar diretamente relacionada ao maior teor de argila.

De forma geral, os valores de $\mathrm{Cd}$ no lixiviado foram maiores que os de $\mathrm{Pb}$. Esses resultados podem ser explicados pela maior mobilidade do $\mathrm{Cd}$ em relação ao $\mathrm{Pb}$ decorrente de sua adsorção ou da dessorção que ocorre em função de sua menor afinidade com a superfície adsorvente do solo. Isso tem implicação no tipo de ligação (específica ou não-específica) e sua interação com os atributos químicos $(\mathrm{pH}, \mathrm{CTC}$, matéria orgânica) e mineralógicos (óxidos de $\mathrm{Fe} \mathrm{e} \mathrm{Al}$ ) (Costa et al., 2007; Pierangeli et al., 2001a,b, 2003, 2005, 2007).

Pode-se observar, no Neossolo Quartzarênico (Figura 4a) e no Latossolo Vermelho (Figura 4b), que a quantidade de $\mathrm{Cd}$ diminui com o aumento da adição da lama da mineração de $\mathrm{Al}$, apresentando, ambos os solos, comportamento quadrático. A lama da mineração de $\mathrm{Al} \mathrm{a} \mathrm{1,00} \mathrm{e} \mathrm{2,00} \mathrm{\%} \mathrm{no} \mathrm{Neossolo}$ Quartzarênico foi mais eficiente em reduzir a concentração de $\mathrm{Cd}$ que os outros amenizantes (calcário, silicato e turfa); no Latossolo Vermelho, foi mais eficiente que o silicato e a turfa, e não diferiu do calcário. No caso do $\mathrm{Pb}$ (Figura 4c), embora seu modelo também tenha sido polinomial quadrático, seu comportamento foi inverso daquele apresentado pelo $\mathrm{Cd}$, ou seja, ocorreu uma redução seguida de um aumento de sua concentração no lixiviado com as maiores quantidades da lama da mineração de $\mathrm{Al}$ aplicada. A aplicação desse amenizante a 1,00 \% não diferiu dos outros amenizantes (calcário, silicato e turfa), no entanto a concentração de $\mathrm{Pb}$ no lixiviado superou os demais na taxa de aplicação de $2,00 \%(\mathrm{RQ}$ 2,00 LMA). Este fato se deve provavelmente ao maior valor de $\mathrm{pH}$ e, conseqüentemente, à maior dispersão do solo e solubilização da matéria orgânica, provocando o arraste principalmente do $\mathrm{Pb}$ por esse elemento apresentar maior afinidade com os colóides inorgânicos e orgânicos quando comparado ao Cd (McBride, 1994). Embora não tenha sido quantificado, ficou evidente pela turbidez que os lixiviados dos tratamentos com maiores valores de $\mathrm{pH}$ apresentaram maior concentração desses colóides solúveis (cor amarelada). No Latossolo Vermelho, as concentrações de $\mathrm{Pb}$ não deferiram entre os tratamentos. Vale ressaltar que o lixiviado analisado não foi filtrado e que parte das quantidades de $\mathrm{Cd}$ e $\mathrm{Pb}$ determinadas pode estar na forma não disponível por encontrarem-se adsorvidos a partículas, caso não ocorra nenhuma mudança que altere sua labilidade. Este fato já foi discutido anteriormente, com base na figura 3 e nos resultados encontrados no trabalho realizado por Lombi et al. (2004).

Solos contaminados com metais e tratados com lama da mineração de $\mathrm{Al}$ e cinzas em colunas de lixiviação já foram estudados por Ciccu et al. (2003) quanto ao comportamento de metais em eluentes. Foi observado que as quantidades de metais nos eluentes foram maiores no início e tenderam a diminuir rapidamente nos primeiros dias. O efeito dessa redução foi atribuído à natureza alcalina dos materiais (como lama da mineração de $\mathrm{Al}$ e cinzas) e devido a constituintes potenciais capazes de adsorver os elementos-traço. Resultados semelhantes foram evidenciados por Bertocchi et al. (2006), ao trabalharem também com colunas de lixiviação. Pelos teores de metais no lixiviado, estes autores puderam concluir que a lama da mineração de $\mathrm{Al}$ mostrou-se eficiente em remover $\mathrm{As}, \mathrm{Pb}$ e $\mathrm{Zn}$, provavelmente devido à sua melhor capacidade de se adaptar aos rejeitos de mina altamente ácidos usados no experimento.

\section{Efeito dos amenizantes sobre os teores de $\mathbf{C d}$ e Pb na planta e no desenvolvimento da Brachiaria decumbens}

As produções de matéria seca da parte aérea (MSPA) e de raízes (MSR), respectivamente no Neossolo Quartzarênico (Figura 5a,c) e no Latossolo Vermelho (Figura 5b,d), aumentaram com a adição crescente da lama da mineração de Al. De maneira geral, as produções de matéria seca de parte aérea e raiz foram inferiores nos tratamentos aplicados ao Neossolo Quartzarênico em relação aos tratamentos aplicado ao Latossolo Vermelho. A maior produção de matéria seca do Latossolo, quando comparados com o Neossolo, se deve à maior capacidade do Latossolo em reter os metais, reduzindo suas concentrações na solução do solo e possibilitando, assim, melhor desenvolvimento de plantas. Carneiro et al. (2002) avaliaram o 
comportamento de espécies herbáceas em relação ao excesso de Cd e Zn em Latossolo Vermelho ácrico típico coletado na profundidade de 0-0,20 $\mathrm{m}$ e contaminado pela mistura em diferentes proporções com um solo antropogênico de uma área de deposição de rejeitos industriais. Eles constataram que a maioria das espécies apresentou redução no crescimento com o aumento da concentração desses elementos no solo (teor máximo de Cd nesse solo extraído pelo Mehlich-1 igual a $\left.85 \mathrm{mg} \mathrm{dm}^{-3}\right)$.

Observou-se que o amenizante reduziu a disponibilidade do $\mathrm{Cd}$ e do $\mathrm{Pb}$, sendo os melhores resultados obtidos nas produções de matéria seca de raiz e da parte aérea, quando foi utilizado o subproduto a 1,00\% em ambos os solos. Na dose 2,00\%, houve uma pequena redução, o que pode ser atribuído, provavelmente, ao sódio e ao maior valor de $\mathrm{pH}$, por indisponibilizar alguns nutrientes. As produções de matéria seca de parte aérea e raiz do Neossolo Quartzarênico com a lama da mineração de $\mathrm{Al}$ aplicada a 1,00 e 2,00 \% não diferiram daquela dos outros amenizantes (calcário, silicato e turfa). Já no Latossolo Vermelho, essas mesmas doses não diferiram no amenizante turfa, e foram superiores ao silicato e inferiores ao calcário. Vale ressaltar que todos os amenizantes testados em ambos os solos tiveram suas produções inferiores à do solo nãocontaminado. No entanto, ficou comprovada a eficiência dos amenizantes em reduzir a disponibilidade de elementos-traço, tornando o ambiente mais favorável ao desenvolvimento de plantas. Estudo semelhante a esse foi conduzido em um experimento no qual utilizaram-se diferentes doses de carbonato, gesso, vermicomposto, serragem e solomax, em solo contaminado com $\mathrm{Zn}, \mathrm{Cd}, \mathrm{Cu}$ e $\mathrm{Pb}$. Foi possível constatar alterações na disponibilidade dos metais no solo devido aos efeitos diferenciados dos tratamentos e também que o carbonato foi o material mais eficaz em reduzir a disponibilidade dos metais, especialmente de Cd e Zn, para Mimosa caesalpiniaefolia (Ribeiro-Filho et al., 2001).

Com relação à redução da toxicidade dos metais nos tratamentos contendo o Neossolo Quartzarênico, deve-se considerar o teor de P desse solo (Quadro 1). Os maiores valores desse elemento podem estar contribuindo para a redução da toxidez dos metais através da formação de formas insolúveis (Paim et al., 2006). Outra forma de redução da disponibilidade dos metais pelo fosfato seria através da disponibilização de grupos fosfatos de superfície nos quais os cátions poderiam ser adsorvidos formando complexos ternários (McBride, 1994; Guilherme \& Anderson, 1998) ou através do aumento do balanço líquido de carga negativa promovido pela adsorção do fosfato na superfície dos minerais (McBride, 1994). A primeira hipótese é considerada mais provável, porque há concentração molar de $\mathrm{P}$ disponível no Neossolo Quartzarênico $\left(4,8 \mathrm{mmol}_{\mathrm{c}} \mathrm{dm}^{-3}\right)$ superior às concentrações semitotais de $\mathrm{Cd}\left(0,4 \mathrm{mmol}_{\mathrm{c}} \mathrm{dm}^{-3}\right)$ e $\mathrm{Pb}$ $\left(1,5 \mathrm{mmol}_{\mathrm{c}} \mathrm{dm}^{-3}\right)$, sendo as quantidades de $\mathrm{P}$ suficientes
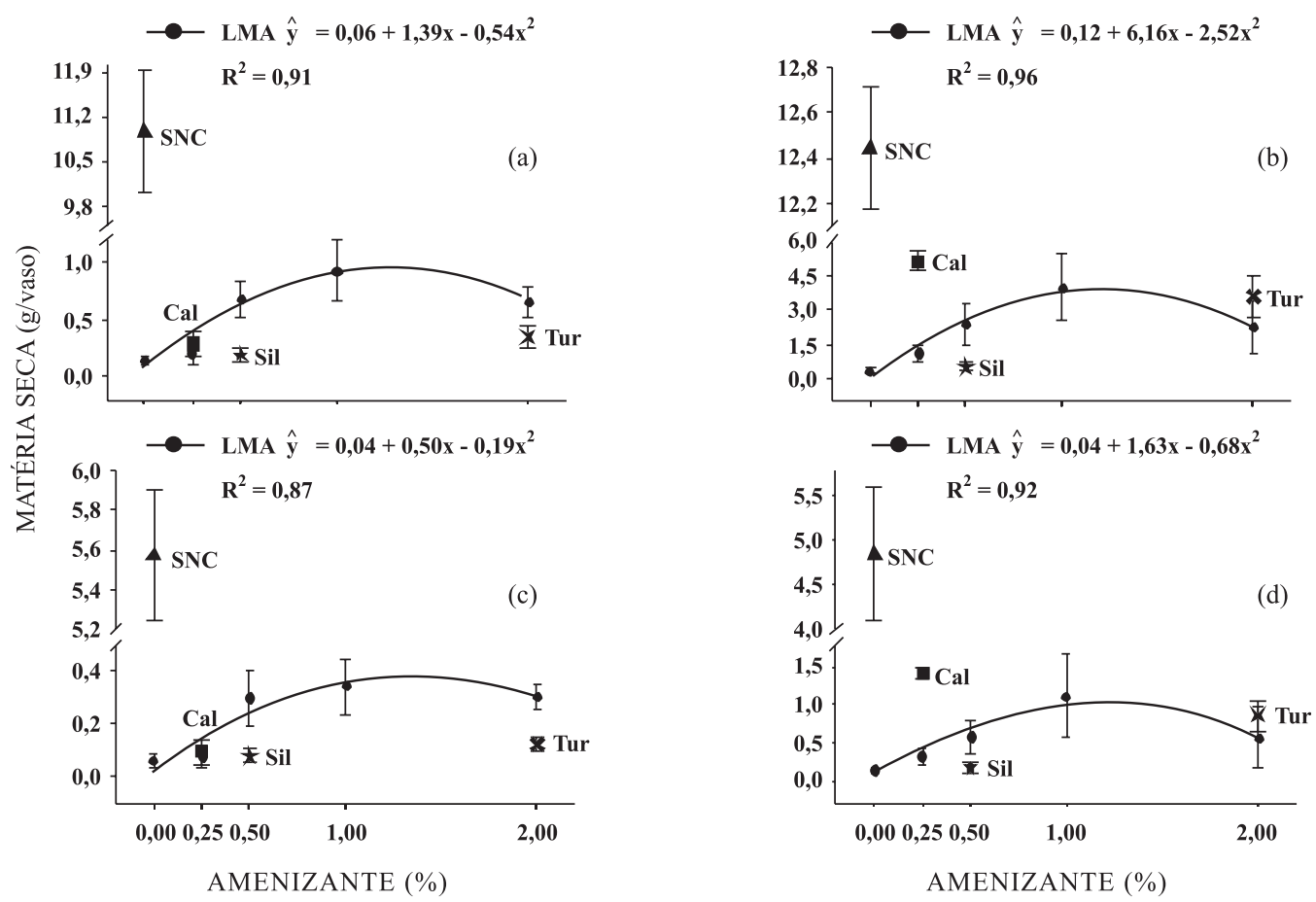

Figura 5. Valores médios da matéria seca da parte aérea (MSPA) e raiz (MSR) de Brachiaria decumbens (g/vaso), respectivamente, do Neossolo Quartzarênico (a e c) e do Latossolo Vermelho (b e d) contaminados com Cd e Pb. LMA: lama da mineração de Al, SNC: solo não-contaminado, Cal: calcário, Sil - silicato e Tur: turfa. 
para formar precipitado. Já as duas últimas hipóteses são consideradas menos prováveis, devido à quantidade de $\mathrm{P}$ e à granulometria e mineralogia do Neossolo Quartzarênico e ainda levando-se em conta os dados de Pierangeli et al. (2004), que verificaram efeito da adição de $1 \mathrm{~g} \mathrm{~kg}^{-1}\left(32,3 \mathrm{mmol}_{\mathrm{c}} \mathrm{kg}^{-1}\right)$ de $\mathrm{P}$ no prétratamento de Latossolos somente para o $\mathrm{Pb}$ em amostras de horizontes B. No entanto, mesmo havendo essas possibilidades, vale lembrar que a quantidade de fosfato foi semelhante em todos os tratamentos com o Neossolo Quartzarênico e que, mesmo assim, foi evidente o efeito desses metais na produção da Brachiaria decumbens, o que foi comprovado pelas baixas produções de MSPA e MSR obtidas no tratamento com o solo contaminado sem amenizante (RQ 0,00 LMA). Dessa forma, embora o $P$ possa estar contribuindo como um amenizante, devese considerar o efeito da lama da mineração de $\mathrm{Al}$ em reduzir a toxicidade desses elementos, proporcionando maior produção de matéria seca.

Estudo comparando a eficiência da lama da mineração de $\mathrm{Al}$ com o calcário e a beringita na redução da fitotoxicidade de elementos-traço foi conduzido para avaliar as respostas de um conjunto de indicadores biológicos, como crescimento de plantas, consumo de metais e o tamanho, a funcionalidade e a diversidade de comunidades microbianas dos solos (Lombi et al., 2002a). Os autores constataram que os três amenizantes reduziram a fitotoxicidade dos elementos-traço avaliados, aumentando a produção e diminuindo a concentração deles nas plantas. O calcário teve um efeito positivo na amenização da toxicidade dos metais, entretanto a longevidade desse efeito pode ser curta, quando comparada com a da lama e a outros materiais com óxidos de $\mathrm{Fe}$ e $\mathrm{Al}$, nos quais o processo de fixação pode aumentar a retenção de metais com o tempo.

As concentrações de $\mathrm{Cd}\left(\mathrm{mg} \mathrm{kg}^{-1}\right)$ na matéria seca da parte aérea (Figura 6a,b) foram bem maiores que as de $\mathrm{Pb}$ (Figura 6c,d). Os efeitos dos amenizantes foram mais pronunciados para o $\mathrm{Cd}$ e $\mathrm{Pb}$ nos tratamentos usando Neossolo Quartzarênico (Figura 6a e c), quando comparados com os tratamentos usando o Latossolo Vermelho (Figura 6b,d). Os Neossolos, devido à sua constituição pobre em argilas, óxidos e matéria orgânica, apresentam menor capacidade de manter os metais retidos quando comparado com o Latossolo. Isso significa maior concentração dos metais na solução do solo e, conseqüentemente, maior fitodisponibilidade. Portanto, neste solo, o efeito do amenizante foi mais evidente, dadas as suas próprias características oxídica e alcalina. Estes efeitos foram parcialmente mascarados no Latossolo, devido à sua constituição já naturalmente oxídica.

Resultados semelhantes foram também observados em experimento conduzido para se avaliar o efeito de $\mathrm{Cd}$ e Zn no crescimento de arroz em dois solos que receberam doses crescentes de lodo de esgoto enriquecido com metais (Oliveira et al., 2005). Foi constatado que a produção de matéria seca total em todas as doses aplicadas, ou mesmo na ausência de lodo, se manteve superior no Latossolo VermelhoAmarelo, quando comparado com o Argissolo Vermelho-Amarelo. Os autores atribuíram este fato aos maiores teores de argila, de óxidos e de matéria orgânica no Latossolo, que, provavelmente, permitiram que quantidade maior de $\mathrm{Cd}$ fosse adsorvida especificamente, diminuindo a disponibilidade e os riscos de toxidez desses elementos para as plantas.

Os tratamentos com amenizante lama da mineração de $\mathrm{Al}$ ao Neossolo Quartzarênico reduziram as concentrações de $\mathrm{Cd}\left(\mathrm{mg} \mathrm{kg}^{-1}\right)$ na matéria seca da parte aérea, seguindo um modelo quadrático (Figura 6a). No Latossolo Vermelho, não houve diferenças entre as concentrações de Cd com as doses do amenizante (Figura 6b). As concentrações de $\mathrm{Cd}$ na matéria seca da parte aérea quando a lama da mineração de Al foi aplicada a 1,00 e 2,00 \% foram menores que os demais amenizantes (calcário, silicato e turfa) no Neossolo Quartzarênico. No Latossolo, não foram observadas diferenças entre os amenizantes. Em ambos os solos, as concentrações de Cd na matéria seca foram superiores às do solo não-contaminado, embora tenha sido observado para a cultura do arroz, que o $\mathrm{Cd}$ e Zn se concentraram nas raízes das plantas, apresentando baixa translocação para as folhas (Oliveira et al., 2005).

$\mathrm{O}$ efeito de doses crescentes de $\mathrm{Cd}$ sobre o crescimento e a nutrição mineral de mudas de duas espécies de eucalipto foi avaliado em um experimento com solução nutritiva (Soares et al., 2005). Verificouse um efeito negativo acentuado no crescimento das duas espécies, com o aumento das doses de $\mathrm{Cd}$ na solução, o que também inibiu o desenvolvimento de suas raízes. A dose crítica para reduzir $10 \%$ na matéria seca da parte aérea foi baixa: 2,4 e 1,5 $\mu \mathrm{mol} \mathrm{L}{ }^{-1}$ para as espécies Eucalyptus maculata e Eucalyptus urophylla, respectivamente. Os níveis críticos de toxidez na parte aérea foram de $14,5 \mathrm{mg} \mathrm{kg}^{-1} \mathrm{em} E$. maculata e $10,8 \mathrm{mg} \mathrm{kg}^{-1}$ de Cd em E. urophylla. Foi também observado que o $\mathrm{Cd}$ reduziu a translocação de $\mathrm{Cu}$ em até $24 \mathrm{mg} \mathrm{kg}^{-1}$ para $E$. maculata e $10,8 \mathrm{mg} \mathrm{kg}^{-1}$ para $E$. urophylla, e a translocação de Fe caiu, em média, $36 \%$ para as duas espécies. Embora esses autores tenham trabalhado com espécies arbóreas em solução nutritiva, resultados comprovam a toxidez do elemento $\mathrm{Cd}$ e, principalmente, sua interferência no transporte de Fe, elucidando uma das possíveis causas da deficiência desse elemento apresentada no estudo, no qual a concentração de Cd na MSPA foi mais elevada, alcançando valores de até $80 \mathrm{mg} \mathrm{kg}^{-1}$ no Neossolo Quartzarênico sem amenizante (RQ 0,00 LMA) (Figura 6a,b).

As concentrações de $\mathrm{Pb}\left(\mathrm{mg} \mathrm{kg}^{-1}\right)$ na MSPA reduziram-se com o aumento da quantidade do amenizante lama da mineração de Al no Neossolo Quartzarênico, seguindo um modelo quadrático 

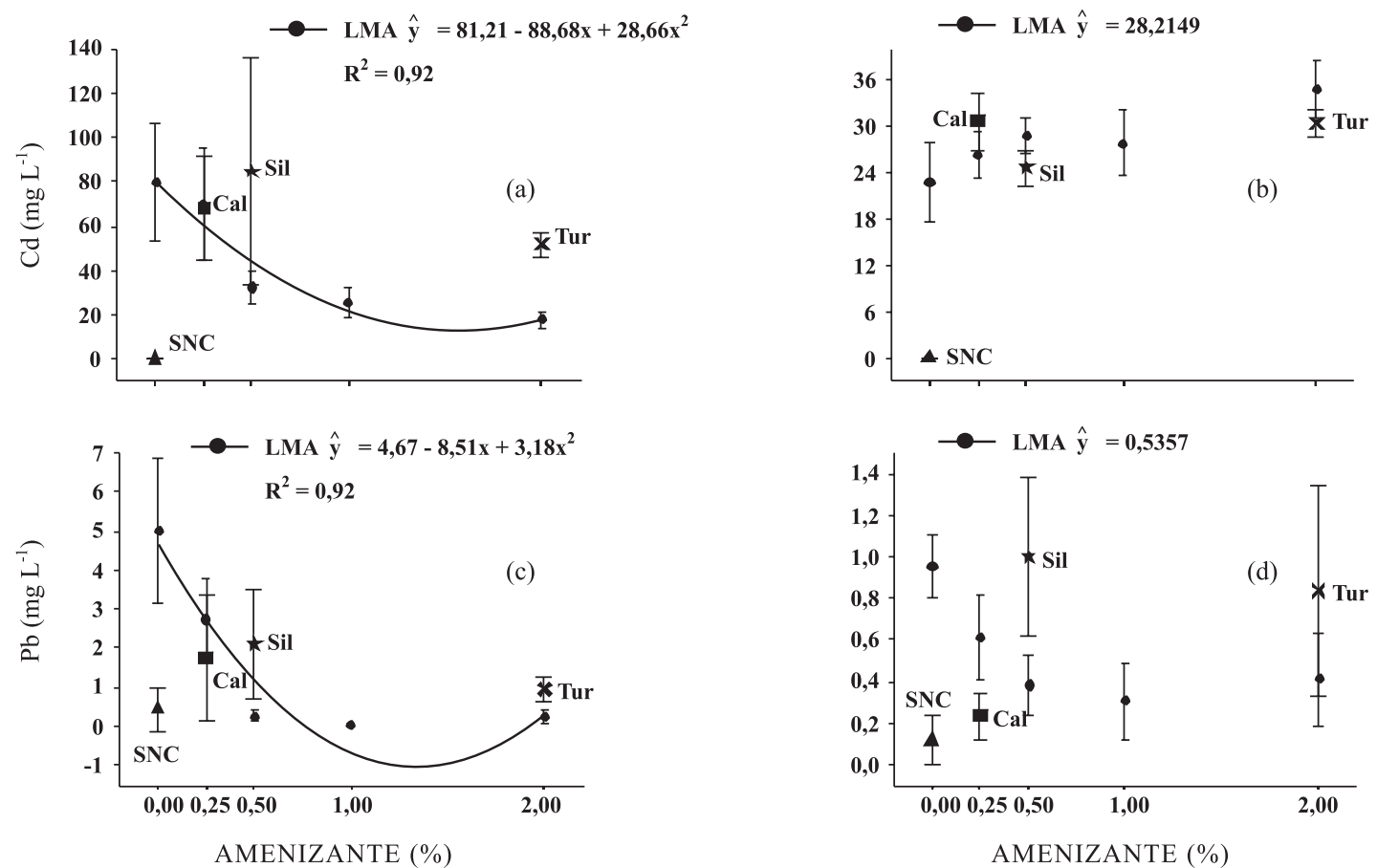

Figura 6. Concentração de $\mathrm{Cd}$ e de $\mathrm{Pb}$ na matéria seca da parte aérea (MSPA) de Brachiaria decumbens $\left(\mathrm{mg} \mathrm{kg}^{-1}\right)$, respectivamente, no Neossolo Quartzarênico (a e c) e no Latossolo Vermelho (b e d) contaminados com Cd e Pb. LMA: lama da mineração de Al, SNC: solo não-contaminado, Cal: calcário, Sil: silicato e Tur: turfa.

(Figura 6c). No Latossolo Vermelho, não foram observadas diferenças entre as quantidades aplicadas de lama da mineração de Al. Nas quantidades aplicadas de 1,00 e 2,00 \% da lama da mineração de Al no Neossolo Quartzarênico (Figura 6c), as concentrações de $\mathrm{Pb}$ não diferiram no amenizante turfa e foram menores que nos amenizantes calcário e silicato. No Latossolo Vermelho, essas mesmas doses não diferiram do demais amenizantes. Ambos os solos não-contaminados foram semelhantes às quantidades de lama da mineração de $\mathrm{Al}$ a 1,00 e 2,00 \%.

A toxidez de elementos-traço em solos contaminados pode impossibilitar o desenvolvimento de plantas. No entanto, a simples utilização de amenizantes, como o calcário e outros, pode possibilitar o desenvolvimento de plantas por meio da redução da toxicidade desses elementos. Accioly et al. (2004) constataram os efeitos do calcário sobre a disponibilidade de $\mathrm{Cd}$ e $\mathrm{Zn}$, teores na parte aérea e crescimento das plantas, indicando o potencial desse corretivo como agente amenizante da toxidez de $\mathrm{Cd}$ e $\mathrm{Zn}$ em mudas de Eucalyptus camaldulensis em solos contaminados. Sucessivas aplicações de lodo de esgoto sobre o acúmulo de elementos-traço em plantas de cana-de-açúcar foram avaliadas por Oliveira \& Mattiazzo (2001). Eles constataram que as concentrações de $\mathrm{Cd}, \mathrm{Cr}, \mathrm{Ni}$ e $\mathrm{Pb}$ nas amostras de plantas de cana-de-açúcar ficaram abaixo dos limites de determinação do método analítico empregado e, no caldo, a presença de $\mathrm{Cd}$, $\mathrm{Cr}$ e Ni ficou abaixo de $0,02 \mathrm{mg} \mathrm{kg}^{-1}$.
Um estudo foi conduzido em casa de vegetação para a determinação dos efeitos da lama da mineração de Al na labilidade e biodisponibilidade de metais em solo, na produção de biomassa e no consumo de metais (Friesl et al., 2004). Foi possível constatar, com base nos resultados, que a aplicação de lama da mineração de $\mathrm{Al}$ em solo contaminado com elementos-traço pode reduzir as frações de metal lábil no solo e, conseqüentemente, a acumulação de $\mathrm{Cd}$, Ni e $\mathrm{Zn}$ nas plantas. Entretanto, a adição de lama em até $5 \%$ com base em peso causou mais desvantagens que vantagens, pois reduziu a labilidade de $\mathrm{Cd}$, Ni, Zn e $\mathrm{Pb}$ em solos e diminuiu a acumulação de $\mathrm{Cd}$, Ni e Zn nas plantas de milho, porém aumentou a labilidade e solubilidade de As, Cu, Cr e V no solo. Os autores sugerem que as taxas de aplicação devem ser ajustadas de acordo com as condições de solo (por exemplo, $\mathrm{pH}$ ) e, em alguns casos, a remoção de poluentes associados à lama da mineração de $\mathrm{Al}$, usando colunas de lixiviação, pode ser necessária.

\section{CONCLUSÕES}

1. Os amenizantes contribuíram para aumentar o $\mathrm{pH}$ dos lixiviados do Neossolo Quartzarênico e do Latossolo Vermelho, tendo este último apresentado menor valor de condutividade eletrolítica quando comparado ao primeiro. 
2. Os teores de $\mathrm{Cd}$ nos lixiviados filtrados (fração solúvel) foram os mesmos para os lixiviados nãofiltrados, enquanto os de $\mathrm{Pb}$ foram inferiores nos lixiviados filtrados.

3. As quantidades de $\mathrm{Cd}$ nos lixiviados diminuíram com a aplicação do subproduto, tanto no Neossolo Quartzarênico quanto no Latossolo Vermelho, e as de $\mathrm{Pb}$ apresentaram comportamentos distintos em ambos os solos e doses.

4. As produções de matéria seca de raiz e parte aérea de Brachiaria decumbens foram maiores no Latossolo Vermelho do que no Neossolo Quartzarênico, e o aumento na taxa de aplicação do subproduto lama da mineração de $\mathrm{Al}$ em ambos os solos, até 1,00 \%, tendeu a aumentar a produção de matéria seca.

5. As quantidades de Cd na matéria seca da parte aérea de Brachiaria decumbens foram mais elevadas que as de $\mathrm{Pb}$.

\section{AGRADECIMENTOS}

À FAPEMIG e à ALCOA, pela concessão de bolsa e financiamento do projeto.

\section{LITERATURA CITADA}

ACCIOLY, A.M.A.; SIQUEIRA, J.O.; CURI, N. \& MOREIRA, F.M.S. Amenização do calcário na toxidez de zinco e cádmio para mudas de Eucalyptus camaldulensis cultivadas em solo contaminado. R. Bras. Ci. Solo, 28:775-783, 2004.

ACCIOLY, A.M.A. \& SIQUEIRA, J.O. Contaminação química e biorremediação do solo. In: NOVAIS, R.F.; ALVAREZ V., V. H. \& SCHAEFER, C.E.G.R., eds. Tópicos em ciência do solo. Viçosa, MG, Sociedade Brasileira de Ciência do Solo, 2000. v. 1. p.299-352.

BERTOCCHI, A.F.; GHIANI, M.; PERETTI, R. \& ZUCCA, A. Red mud and fly ash for remediation of mine sites contaminated with $\mathrm{As}, \mathrm{Cd}, \mathrm{Cu}, \mathrm{Pb}$ and $\mathrm{Zn}$. J. Hazard. Mater., 134:112-119, 2006.

BRASIL. Ministério da Agricultura e Reforma Agrária. Regras para análise de sementes. Brasília, CLAV/DNDV; SNAD/ MA, 1992. 365p.

BRUNORI, C.; CREMISINI, C.; MASSANISSO, P.; PINTO, V. \& TORRICELLI, L. Reuse of a treated red mud bauxite waste: Studies on environmental compatibility. J. Hazard. Mater., 117:55-63, 2005.

CARNEIRO, M.A.C.; SIQUEIRA, J.O. \& MOREIRA, F.M.S. Comportamento de espécies herbáceas em misturas de solo com diferentes graus de contaminação com metais pesados. Pesq. Agropec. Bras., 37:1629-1638, 2002.
COMPANHIA DE TECNOLOGIA DE SANEAMENTO AMBIENTAL - CETESB. Valores orientadores para solos e águas subterrâneas no Estado de São Paulo. São Paulo, 23 de novembro de 2005. Disponível em: <http:// w w w.cetesb.sp.gov.br/solo/relatorios/ tabela_valores_2005.pdf>. Acesso em 21 maio 2006.

COSTA, C.N.; MEURER, E.J.; BISSANI, C.A. \& TEDESCO, M.J. Fracionamento seqüencial de cádmio e chumbo em solo. Ci. Rural, 37:1323-1328, 2007.

COSTA, E.T.S.; GIUILHERME, L.R.G.; CURI, N.; OLIVEIRA, L.C.A.; LOPES, G. \& VISIOLI, E.L. Caracterização de subproduto da indústria de alumínio e seu uso na retenção de cádmio e chumbo em sistemas monoelementares. Quimica Nova, 2008. Aceito para publicação.

CICCU, R.; GHIANI, M.; SERCI, A.; FADDA, S.; PERETTI, R. \& ZUCCA, A. Heavy metal immobilization in the miningcontaminated soils using various industrial wastes. Miner. Eng., 16:187-192, 2003.

DEPARTAMENTO NACIONAL DE PRODUÇÃO MINERAL DNPM. Anuário mineral brasileiro - 2006. Disponível em: $<$ http://www.dnpm.gov.br>. Acesso em jul. de 2008.

EMPRESA BRASILEIRA DE PESQUISA AGROPECUÁRIA EMBRAPA. Centro Nacional de Pesquisa em Solos. Manual de métodos de análise de solo. Rio de Janeiro, 1997. 212p.

FRIESL, W.; FRIEDL, J.; PLATZER, K.; HORAK, O. \& GERZABEK, M.H. Remediation of contaminated agricultural soils near a former $\mathrm{Pb} / \mathrm{Zn}$ smelter in Austria: Batch, pot and field experiments. Environ. Pollut., 144:4050, 2006.

FRIESL, W.; HORAK, O. \& WENZEL, W.W. Immobilization of heavy metals in soils by the application of bauxite residues: Pot experiments under field conditions. J. Plant Nutr. Soil Sci., 167:54-59, 2004.

GUILHERME, L.R.G. \& ANDERSON, S.J. Copper sorption kinetics and sorption hysteresis in two oxide-rich soils (Oxisols): Effect of phosphate pretreatment. In: JENNE, E.A., ed. Adsorption of metals by geomedia: Variables, mechanisms, and model applications. San Diego, Academic Press, 1998. p.209-228.

GUPTA, V.K. \& SHARMA, S. Removal of cadmium and zinc from aqueous solutions using red mud. Environ. Sci. Technol., 36:3612-3617, 2002.

KABATA-PENDIAS, A. \& PENDIAS, H. Trace elements in soils and plants. 3.ed. Boca Raton, CRC Press, 2001. 413p.

LOMBI, E.; HAMON, R.E.; WIESHAMMER, G.; McLAUGHLIN, M.J. \& McGRATH, S.P. Assessment of the use of industrial by-products to remediate a copperand arsenic-contaminated soil. J. Environ. Qual., 33:902910, 2004

LOMBI, E.; ZHAO, F.J.; WIESHAMMER, G.; ZHANG, G. \& McGRATH, S.P. In situ fixation of metals in soils using bauxite residue: Biological effects. Environ. Pollut., 118:445-452, 2002a. 
LOMBI, E.; ZHAO, F.J.; ZHANG, G.; SUN, B.; FITZ, W.; ZHANG, H. \& McGRATH, S.P. In situ fixation of metals in soils using bauxite residue: Chemical assessment. Environ. Pollut., 118:435-443, 2002b.

MALAVOLTA, E.; VITTI, G.C. \& OLIVEIRA, S.A. Avaliação do estudo nutricional das plantas: Princípios e aplicações. Piracicaba, POTAFOS, 1989. 210p.

McBRIDE, M.B. Environmental chemistry of soils. New York, University Press, 1994. 406p.

MULLIGAN, C.N.; YONG, R.N. \& GIBBS, B.F. Remediation technologies for metal-contaminated soils and groundwater: An evaluation. Eng. Geol., 60:193-207, 2001.

OLIVEIRA, C.; SOBRINHO, N.M.B.A.; MARQUES, V.S. \& MAZUR, N. Efeitos da aplicação de lodo de esgoto enriquecido com cádmio e zinco na cultura do arroz. R. Bras. Ci. Solo, 29:109-116, 2005.

OLIVEIRA, F.C. \& MATTIAZZO, M.E. Metais pesados em Latossolo tratado com lodo de esgoto e em plantas de cana-de-açúcar. Sci. Agric., 58:581-593, 2001.

PAIM, L.A.; CARVALHO, R.; ABREU, C.M.P. \& GUERREIRO, M.C. Estudo dos efeitos do silício e do fósforo na redução da disponibilidade de metais pesados em áreas de mineração. Química Nova, 29:28-33, 2006.

PÉREZ-DE-MORA, A.; MADRID，F.; CABRERA，F. \& MADEJÓN, E. Amendments and plant cover influence on trace element pools in a contaminated soil. Geoderma, 139:1-10, 2007.

PIERANGELI, M.A.P.; GUILHERME, L.R.G.; CURI, N.; ANDERSON, S.J. \& LIMA, J.M. Adsorção e dessorção de cádmio, cobre e chumbo por amostras de Latossolos prétratadas com fósforo. R. Bras. Ci. Solo, 28:377-384, 2004.

PIERANGELI, M.A.P.; GUILHERME, L.R.G.; CURI, N.; COSTA, E.T.S.; LIMA, J.M.; MARQUES, J.J.G.S.M. \& FIGUEIREDO, L.F.P. Comportamento sortivo individual e competitivo, de metais pesados em Latossolos com mineralogia contrastante. R. Bras. Ci. Solo, 31:819-826, 2007.

PIERANGELI, M.A.P.; GUILHERME, L.R.G.; CURI, N.; SILVA, M.L.N.; LIMA, J.M. \& COSTA, E.T.S. Efeito do pH na adsorção e dessorção de cádmio em Latossolos brasileiros. R. Bras. Ci. Solo, 29:523-532, 2005.
PIERANGELI, M.A.P.; GUILHERME, L.R.G.; CURI, N.; SILVA, M.L.N.; OLIVEIRA, L.R. \& LIMA, J.M. Efeito do $\mathrm{pH}$ na adsorção-dessorção de chumbo em Latossolos brasileiros. R. Bras. Ci. Solo, 25:269-277, 2001a.

PIERANGELI, M.A.P.; GUILHERME, L.R.G.; OLIVEIRA, L.R.; CURI, N. \& SILVA, M.L.N. Efeito da força iônica da solução de equilíbrio na adsorção de cádmio em Latossolos brasileiros. Pesq. Agropec. Bras., 38:737-745, 2003.

PIERANGELI, M.A.P.; GUILHERME, L.R.G.; OLIVEIRA, L.R.; CURI, N. \& SILVA, M.L.N. Efeito da força iônica da solução de equilíbrio sobre a adsorção/dessorção de chumbo em Latossolos brasileiros. Pesq. Agropec. Bras., 36:1077-1084, 2001b.

RIBEIRO-FILHO, M.R.; SIQUEIRA, J.O.; CURI, N. \& SIMÃO, J.B.P. Fracionamento e biodisponibilidade de metais pesados em solo contaminado, incubado com materiais orgânicos e inorgânicos. R. Bras. Ci. Solo, 25:495-507, 2001.

SILVA, F.C.; SILVA, C.A.; BERGAMASCO, A.F. \& RAMALHO, A.L. Efeito do período de incubação e de doses de compostos de lixo urbano na disponibilidade de metais pesados em diferentes solos. Pesq. Agropec. Bras., 38:403412, 2003.

SOARES, C.R.F.S.; SIQUEIRA, J.O.; CARVALHO, J.G. \& MOREIRA, F.M.S. Fitotoxidez de cádmio para Eucalyptus maculata e E. urophylla em solução nutritiva. R. Árvore, 29:175-183, 2005.

UNITED STATES ENVIRONMENTAL PROTECTION AGENCY - USEPA. Method 3051A: Microwave assisted acid digestion of sediments, sludges, soils, and oils. In: SW-846. Test methods for evaluating solid waste, physical/ chemical methods; Office of solid Waste. Washington, DC, 1998. p.1-20.

VANGRONSVELD, J. \& RUTTENS, A. In-situ reclamation techniques for heavy metal contaminated soils. In: SIQUEIRA, J.O.; MOREIRA, F.M.S.; LOPES, A.S.; GUILHERME, L.R.G.; FAQUIN, V.; FURTINI NETO, A.E. \& CARVALHO, J.G., eds. Inter-relação fertilidade, biologia do solo e nutrição de plantas. Lavras, Sociedade Brasileira de Ciência do Solo, Universidade Federal de Lavras, 1999. p.389-404.

VETTORI, L. Métodos de análise de solos. Rio de Janeiro, Ministério da Agricultura - Equipe de Pedologia e Fertilidade do Solo, 1969. 24p. (Boletim Técnico, 7) 